\title{
Correction to: Flow-mediated dilation and heart failure: a review with implications to physical rehabilitation
}

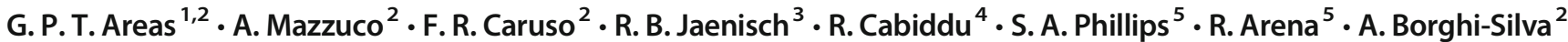

Published online: 11 November 2019

(C) Springer Science+Business Media, LLC, part of Springer Nature 2019

\section{Correction to: Heart Fail Rev}

https://doi.org/10.1007/s10741-018-9719-7

The scholarship support information in Acknowledgement was missing. It should read:

This study was financed in part by the Coordenação de Aperfeiçoamento de Pessoal de Nível Superior - Brasil (CAPES) - Finance Code 001" and FAPESP 2015/26501-1.

The authors regret the errors.

Publisher's note Springer Nature remains neutral with regard to jurisdictional claims in published maps and institutional affiliations.

The online version of the original article can be found at https://doi.org/ 10.1007/s10741-018-9719-7

A. Borghi-Silva audrey@ufscar.br

1 Physiological Science Departament, Universidade Federal do Amazonas, Manaus, Brazil

2 Cardiopulmonary Physiotherapy Laboratory, Universidade Federal de Sao Carlos, Rod. Washington Luis, km 235-SP-310-CEP: 13565-905, Sao Carlos, Sao Paulo, Brazil

3 Universidade Federal de Santa Maria, Santa Maria, Rio Grande do Sul, Brazil

4 Biomedical Engineering, Politecnico di Milano, Milan, Italy

5 University of Illinois at Chicago, Chicago, IL, USA 